\title{
PIAGET PEDAGOGO? A criança, o espaço geográfico e a epistemologia do professor
}

\author{
Leonardo Pinto dos Santos ${ }^{1}$ \\ Victória Sabbado Menezes 2 \\ Roselane Zordan Costella ${ }^{3}$
}

\begin{abstract}
Resumo: Este artigo pretende realizar uma relação entre três epistemologias: apriorista, empirista e construtivista com a vida do professor. $\mathrm{O}$ foco será a epistemologia genética de Jean Piaget e sua potencialidade para o estudo do espaço geográfico, tecendo uma reflexão entorno de concepções epistemológicas de educação que assentam as práticas pedagógicas dos professores de diferentes campos do conhecimento. Ao afirmar que a prática educativa se apoia em determinada concepção de educação, torna-se necessário compreendê-las para melhor pensar nas trajetórias de uma vida docente que se preocupe em uma formação cidadã de meninos e meninas que dialogam conosco dentro do ambiente escolar.
\end{abstract}

Palavras-chave: Construtivismo. Geografia. Jean Piaget.

\section{PIAGET EDUCATOR?}

\section{The child, the geographic space and the epistemology of the teacher}

\begin{abstract}
This article intends to make a relation between three epistemologies: apriorist, empiricist and constructivist with the life of the teacher. The focus will be the genetic epistemology of Jean Piaget and its potential for the study of geographic space, weaving a reflection around epistemological conceptions of education that are based on the pedagogical practices of teachers from different fields of knowledge. When affirming that the educational practice relies on a particular conception of education, it becomes necessary to understand them to better think about the trajectories of a teaching life that is concerned with a citizen formation of boys and girls who dialogue with us within the school.
\end{abstract}

Keywords: Constructivism. Geography. Jean Piaget.

\footnotetext{
${ }^{1}$ Doutorando em Geografia pela Universidade Federal de Santa Maria. É mestre em Geografia pela Universidade Federal do Rio Grande do Sul (2015). Professor da Rede Estadual do Rio Grande do Sul SEDUC/RS e integrante do Núcleo de Pesquisas e Estudos Geográficos do Instituto Federal de Educação Tecnológica do Rio Grande do Norte, do Grupo de pesquisa Formação Continuada de Professores da Universidade Federal do Rio Grande do Sul e do Grupo de Estudos Geografia, Trabalho e Ambiente da Universidade Federal de Santa Maria. E-mail: leonardoufsm@hotmail.com

2 Doutoranda em Geografia pelo Programa de Pós-Graduação em Geografia da UFRGS na linha de pesquisa em Ensino de Geografia. Mestra em Geografia pelo Programa de Pós-Graduação em Geografia da Universidade Federal do Rio Grande do Sul (UFRGS). É integrante do Núcleo de Estudos em Educação e Geografia (NEEGEO/UFRGS). E-mail: victoriasabbado@ gmail.com

${ }^{3}$ Doutora pela em Geografia pela Universidade Federal do Rio Grande do Sul. Docente na Faculdade de Educação FACED/UFRGS, coordena a Coordenadoria das Licenciaturas da UFRGS/COORLICEN gestão 2015 - 2017. Coordena Institucionalmente o Programa de Incentivo de Bolsas de Iniciação à Docência PIBID/UFRGS gestão 2013 - 2018. E-mail: ro.paulo@terra.com.br
} 


\section{REVISTA ELETRÔNICA \\ DA GRADUAÇÃO/PÓS-GRADUAÇÃOO EM EDUCAÇÃO}

UFG/REJ

\section{TTNERARIIIS \\ REFLECTIONIS}

ISS N. 1807-9342

Volume 14, N. 2, 2018

\section{INTRODUÇÃO}

Na matemática, já haviam provado no remoto ano de 1837 que seria impossível trisseccionar um ângulo com compasso e régua não marcados. Mas chegando no século XXI, há ainda aqueles que acreditam ter descoberto o tear de fios de ouro, dando panos finais a esta problemática até então tomada como incapaz de ser resolvida.

Em matéria intitulada ' $\mathrm{Na}$ matemática, o impossível é para sempre impossível", questiona-se por que as pessoas não compreendem o caráter definitivo das afirmações matemáticas, seriam loucos! Seria mera ignorância ou seria o que existe de mais humano, a busca pela resposta daquilo que nos deixa com aquela coceira de quero mais.

Nessa mesma matéria de revista, há o apontamento de que "diante do impossível, há sempre coisas produtivas a fazer" (DREHER; SOUSA, 2014, p.33). Esse é o caminho a se seguir neste artigo, que busca expor as três principais epistemologias que regem o docenciar de professores, dando ênfase à construtivista, corrente seguida dentre tantos nomes por Jean Piaget, foco neste trabalho.

Piaget buscou algo que, mesmo em tempos atuais é impossível: compreender como funciona o desenvolvimento cognitivo, da mais tenra idade até a fase adulta. Ele conseguiu apontar alguns caminhos importantes, o que releva a frase de que diante do impossível, há sempre coisas produtivas a fazer.

Seu objetivo sempre foi buscar como o ser humano é capaz de construir algo, desejando entender os mecanismos que levam os adultos a raciocinarem frente a diversos desafios. Mas então por que ele não pesquisou diretamente com adultos, tendo majoritariamente um público infantil em suas pesquisas no Centro Internacional de Epistemologia Genética?

Ao pesquisar com crianças, ele criou um terreno fértil para que seus estudos fossem trazidos para o campo da didática. Como ele estava interessado na apreensão da gênese do conhecimento humano, isso somente seria possível partilhando momentos com crianças, já que "só quem possui uma educação apropriada conhece a impossibilidade sistemática que experimentará um adulto já formado para reconstruir a gênese de suas ideias antes de sua cristalização" (PIAGET; BETH; MAYS, 1974, p.24).

Ao buscar compreender o desenvolvimento humano, Jean Piaget mesmo não desejoso disso, acabou sendo "sequestrado" por educadores das mais diversas áreas do 


\section{REVISTA ELETRÔNICA \\ DA GRADUAÇÃO/PÓS-GRADUAÇÃOO EM EDUCAÇÃO}

UFG/REJ

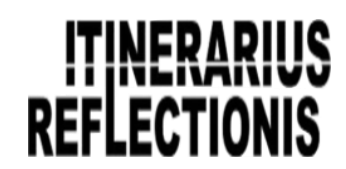

ISS N. 1807-9342

Volume 14, N. 2, 2018

conhecimento, que viam nele e no trabalho de sua equipe uma possibilidade para se entender o seu aluno e uma forma de se engendrar suas práticas pedagógicas as possibilidades dos jovens estudantes.

Um exemplo disso se deu em 1949, quando Piaget visitou o Rio de Janeiro, como representante da UNESCO, tendo recebido neste período o título de Honoris Causa pela Universidade do Brasil. O que foi curioso desta sua passagem por nosso país foi sua irritação por tantas perguntas que envolviam problemas imediatos da educação, uma vez que, seu problema central se desviava mais para o campo da epistemologia, da filosofia das ciências e a relação entre crença e conhecimento (VASCONCELOS, 1996).

Barrelet; Perret-Clermont ([19--], p.09) destacam que "Piaget descrever-se-á como alguém que faz uma digressão pela psicologia para se interrogar, por meio de métodos novos, sobre a questão central da epistemologia. E é talvez a contragosto que é hoje conhecido, antes do mais, como psicólogo e até como pedagogo".

Neste seu movimento por descobrir sobre como a criança constrói conhecimento, ele desenvolveu toda uma construção teórica e prática em torno da ação do sujeito que ele chamou de sujeito epistêmico, ou seja, aquele que produz conhecimento, levando a possibilidade de se entender a Epistemologia Genética como uma Epistemologia da ação.

O sujeito epistêmico, ou sujeito do conhecimento, constitui-se pela sua própria ação. Ele age sobre o meio buscando satisfazer suas necessidades, seus desejos. Essa ação transforma o meio. Ao transformar o meio, buscando assimilá-lo em vista de suas necessidades, o sujeito é confrontado pelas resistências do meio (BECKER, 2012, p.54).

Para este pesquisador, a criança somente se torna capaz de construir algo a partir de sua própria ação, o que desmontava os argumentos de aprioristas e empiristas que defendiam que o conhecimento era algo inato ao indivíduo. As estruturas seriam coisas dadas, como se tudo já estivesse predeterminado no organismo, restando somente esperar que seu organismo amadurecesse. É destas concepções que partem a concepção de aluno como uma folha em branco ou como tábula rasa, tão combatida por Paulo Freire (2011). 


\section{REVISTA ELETRÔNICA \\ DA GRADUAÇÃO/PÓS-GRADUAÇÃO EM EDUCAÇÃO UFG/REJ}

\section{ITINERPARIIUS REFLECTIONIS}

ISSN. 1807-9342

Volume 14, N. 2, 2018

O apriorismo diferencia-se do empirismo no sentido de que o sujeito apresenta estruturas de conhecimento desde seu nascimento, enquanto que na epistemologia empirista o sujeito é tábula rasa. $\mathrm{O}$ empirismo confere uma importância enorme ao exterior, ao mundo físico, de maneira que o objeto determina o sujeito. No modelo apriorista a relação se inverte, pois é o sujeito que determina o objeto. A experiência não assume a centralidade do processo do conhecimento, mas sim o sujeito. Este é responsável pela atividade do conhecimento sem que o meio possua muita participação (MENEZES, 2016, p.63).

Dentro de nosso campo de trabalho, nós professores estamos atrelados a uma ou até mesmo a mais de uma destas epistemologias, sejamos professores do ensino superior, sejamos professores da educação básica. Não há diferenciação, elas nos atingem a todos, mesmo que não seja de forma consciente, como bem destaca Hans Aebli em um dos poucos trabalhos conhecidos que envolvem diretamente a aplicação da teoria piagetiana no campo educacional, tendo o prefácio da obra sendo feito pelo próprio Piaget.

Tal relación entre la didáctica y la psicología, raramente se establece de manera consciente y directa. Y, sin embargo, todo método de enseñanza es solidario con una psicología del niño y de su pensamiento, no explícita, ciertamente, muchas veces, pero tácitamente presupuesta (AEBLI, 1958, p.09).

A pouca compreensão em relação às epistemologias existentes e mesmo a incompreensão dos pressupostos das mesmas por parte do professorado, acaba por influir em pensamentos errôneos sobre as mesmas, o que afeta invariavelmente a sua "utilização" em sala de aula. Ao analisarmos trabalhos como de Marques (2005); Becker (1993) e Menezes (2016), vemos essas incongruências em exemplos práticos e os malefícios que isso proporciona dentro das práticas pedagógicas utilizadas por diferentes grupos de professores.

Portanto, neste artigo iremos introduzir os pressupostos de três epistemologias empirismo, apriorismo e construtivismo - que são utilizadas em diferentes ambientes escolares, dando ênfase ao construtivismo e à teoria piagetiana como potencializadora do entendimento do espaço geográfico, objeto maior da ciência que chamamos de Geografia.

Estamos desejosos de caminhar por trajetos até então considerados impossíveis como é o entendimento da mente humana -, mas por ser impossível, há sempre algo 


\section{REVISTA ELETRÔNICA \\ DA GRADUAÇÃO/PÓS-GRADUAÇÃOO EM EDUCAÇÃO}

UFG/REJ

\section{ITNERARIIIS \\ REFLECTIONIS}

ISS N. 1807-9342

Volume 14, N. 2, 2018

produtivo a se fazer, com o intuito de repensar o papel do professor em uma realidade que necessita objetivar a compreensão do espaço geográfico, para que nele se refaça a sociedade que hoje se pauta mais em valores individuais e do capital do que de igualdade e respeito mútuo.

Como o neurocientista português Damásio (2000, p.18) já destacara: “o que poderia ser mais dificil de conhecer do que conhecer o modo como conhecemos?", vamos seguir por este caminho? Deveríamos, enquanto professores que somos.

\section{EMPIRISMO, APRIORISMO E CONSTRUTIVISMO: suas tensões e relações} entre nós professores

A atividade docente, em geral, é confundida com a prática educativa do sujeito professor. Isto é, atenta-se para o fazer pedagógico, de modo que o olhar é direcionado para as práticas adotadas, as estratégias metodológicas, a forma de avaliação. Contudo, o que se quer ressaltar é que a discussão acerca do exercício docente não pode se restringir ao nível das práticas pedagógicas, propriamente ditas, mas também deve envolver os pressupostos que sustentam tais práticas. Isso quer dizer que a ação educativa é orientada por determinados fundamentos teórico-epistemológicos. Trata-se, portanto, da epistemologia docente.

De acordo com Becker (1993; 2001), há três epistemologias: empirismo, apriorismo e construtivismo. Cada uma destas apresenta características próprias que expressam uma corrente de pensamento. Embora possuam divergências, não significa que um mesmo professor adotará somente uma linha teórico-epistemológica na sua prática de ensino. A prática docente é complexa, assim como nós, seres humanos, professores, somos complexos e contraditórios. Não se pode afirmar que cada educador se apoia, exclusivamente, em uma epistemologia.

Cabe esclarecer que todo professor se fundamenta em corrente(s) epistemológica(s), mesmo que de forma subjacente. Não há processo de ensinoaprendizagem desprovido de intencionalidade. A ação pedagógica ancora-se em princípios e pressupostos que revelam a visão de ensino, de conhecimento, de Educação e de aprendizagem do educador. No entanto, há docentes que não estão cônscios de suas escolhas epistemológicas. Esta constatação reforça a necessidade de uma discussão 


\section{REVISTA ELETRÔNICA \\ DA GRADUAÇÃO/PÓS-GRADUAÇÃO EM EDUCAÇÃO UFG/REJ}

\section{ITINERPARIIUS REFLECTIONIS}

ISSN. 1807-9342

Volume 14, N. 2, 2018

concernente à epistemologia do professor no campo da Educação e, neste caso, especificamente na linha do ensino de Geografia.

Feito os esclarecimentos, buscar-se-á explicitar e distinguir o empirismo, o apriorismo e o construtivismo com base nas considerações de Becker (1993; 2001) a fim de traçar um panorama acerca das epistemologias docentes. A partir da elaboração deste quadro geral, será possível enfocar na corrente construtivista, a qual constitui o terreno teórico de Piaget. Assim, pretende-se tecer relações entre o construtivismo e, especificamente, as contribuições piagetianas, com a problemática da Geografia escolar e a compreensão do espaço geográfico.

Ao imaginar uma sala de aula e os processos de ensino que ocorrem neste espaço, torna-se fácil compreender a epistemologia empirista. Isso porque tal corrente é a mais tradicional, no sentido de ser a mais comumente empregada ao longo dos períodos históricos. O empirismo concebe o aluno como uma tábula rasa, uma folha de papel em branco que deve ser preenchida de conhecimento. Porém este conhecimento provém do exterior, visto que o aluno não apresenta conhecimentos prévios. Dessa maneira:

O sujeito é totalmente determinado pelo mundo do objeto ou pelos meios físico e social. Quem representa este mundo, na sala de aula, é, por excelência, o professor. No seu imaginário, ele, somente ele, pode produzir algum novo conhecimento no aluno. $\mathrm{O}$ aluno aprende se, e somente se, o professor ensina. O professor acredita no mito da transferência do conhecimento: o que ele sabe, não importa o nível de abstração ou de formalização, pode ser transferido ou transmitido para o aluno. Tudo o que o aluno tem a fazer é submeter-se à fala do professor: ficar em silêncio, prestar atenção, ficar quieto e repetir tantas vezes quantas forem necessárias, escrevendo, lendo, etc., até aderir em sua mente, o que o professor deu (BECKER, 2001, p.18).

Conforme esta corrente, o professor é o dono do saber e tem o papel de transmitir para o aluno. O conhecimento parte do mundo do objeto e determina o sujeito, o que denota uma relação vertical e assimétrica. Da mesma forma, o professor determina o aluno. O conhecimento pode ser entendido como a apreensão de uma verdade, pois não é construído. Dessa maneira, o processo de ensino e aprendizagem é claramente fragmentado. Há aquele responsável por ensinar (o professor) e aqueles responsáveis por aprender (os alunos). A troca, a criação e a produção tornam-se impensáveis de serem desenvolvidas sob esta perspectiva. 


\section{REVISTA ELETRÔNICA \\ DA GRADUAÇÃO/PÓS-GRADUAÇÃOO EM EDUCAÇÃO}

UFG/REJ

\section{ITHAERARIIIS \\ REFLECTIONIS}

ISS N. 1807-9342

Volume 14, N. 2, 2018

A epistemologia empirista possui uma estreita relação com a pedagogia diretiva. A relação entre professor e aluno, a qual pauta-se na transferência de conhecimentos, é marcada pelo autoritarismo do primeiro e a submissão do segundo. Ou seja, cabe ao aluno assumir uma postura passiva, obedecer ao professor sem questioná-lo e manter o silêncio. O professor fala, decide, ensina e os alunos escutam, acatam e aprendem. $\mathrm{O}$ diálogo é impossibilitado, visto que não é permitido aos educandos manifestarem-se já que nada sabem em termos de conhecimento.

Pode-se estabelecer uma ligação entre o empirismo e a pedagogia diretiva com a concepção de educação bancária de Freire. Para o autor, a educação "passa a ser 'o ato de depositar', no qual os alunos são os depósitos e o professor aquele que deposita. Em lugar de comunicar, o professor dá comunicados que os alunos recebem pacientemente, aprendem e repetem. É a concepção "acumulativa” da educação" (FREIRE, 1979, p. 41). Destarte, o ensino torna-se acrítico e reprodutivista.

No que diz respeito ao ensino de Geografia, a presença da epistemologia empirista e da pedagogia diretiva é comum e simples de ser resgatada em nossas memórias de quando estávamos na condição de alunos no ensino básico. Aulas marcadas pela memorização de capitais, classificação de relevo, clima, hidrografia, por exemplo, são as primeiras lembranças que vêm à mente quando se pensa nas aulas de Geografia. Configura-se em uma Geografia cinza, sem vida, desinteressante, apática. Aulas com poucas perguntas, poucas dúvidas, pouca interação.

Depreende-se que um ensino de Geografia ancorado nesta vertente epistemológica e pedagógica resulta em aulas sem sentido para os educandos, uma vez que desconsidera seus interesses e suas dúvidas. Não se tem o intuito de que as aulas sejam participativas e/ou problematizadas. Há muito mais afirmações do que questionamentos, o que é criticado por Kaercher quando o mesmo propõe uma inversão desta lógica. Segundo o autor, "não é só a troca do sinal de exclamação pelo de interrogação, mas sim toda uma virada epistemológica, uma concepção de ensinar que implica o diálogo, a dúvida, o debate, a discordância (ddd's)” (KAERCHER, 2013, p. 26).

Entretanto, o empirismo e a pedagogia diretiva partem da premissa de que o professor detém total poder para desenvolver o processo educativo, de modo que cabe ao aluno apenas aceitar e receber os conhecimentos transferidos. Não há uma 


\section{REVISTA ELETRÔNICA \\ DA GRADUAÇÃO/PÓS-GRADUAÇÃO EM EDUCAÇÃO UFG/REJ}

\section{ITINERPARIIUS REFLECTIONIS}

ISSN. 1807-9342

Volume 14, N. 2, 2018

preocupação com a etapa de desenvolvimento cognitivo que cada educando se encontra, pois todos são considerados como uma folha de papel em branco. É possível traçar um paralelo com as considerações de Marques (2005) que constatou a existência de três tipos de professores que se distinguem de acordo com os níveis que variam no processo do egocentris mo à descentração.

$\mathrm{O}$ primeiro professor nega o aluno, desenvolvendo seu fazer pedagógico somente a partir de sua referência. O segundo professor pensa no aluno a partir de si próprio. Neste, há o interesse em compreender o processo de ensino-aprendizagem, mas o educador ainda não consegue descentrar-se por completo e perceber que o pensamento do aluno se diferencia do seu pensamento. $O$ terceiro professor pensa no aluno a partir do aluno, de maneira que reconhece o outro e coloca-se no lugar do outro a fim de propor situações que possibilitem, de fato, a aprendizagem do aluno de acordo com suas necessidades. Por conseguinte, considera-se que o primeiro tipo de professor, aquele que nega a existência do aluno, conforme Marques (2005), está associado ao que se entende pela epistemologia empirista e a pedagogia diretiva.

Para destacar o que entendemos, por egocentrismo e descentração comentados até aqui, trazemos duas falas de Piaget:

Nós chamamos egocentrismo a indiferenciação do ponto de vista próprio e dos outros, ou da atividade própria e das transformações do objeto. Adotamos esse termo por analogia com antropocentrismo, mas o antropocentrismo da criança só está centrado ainda em sua atividade individual, em oposição à do homem em geral (PIAGET, 1993, p.58).

Uma espécie de revolução copernicana que consiste em descentrar as ações em relação ao próprio corpo, em considerá-lo um objeto entre outros num espaço que os contém a todos, e em ligar as ações dos objetos sob o efeito das coordenações de um sujeito que começa a conhecer-se enquanto fonte ou mesmo enquanto senhor de seus movimentos (PIAGET, 2012, p.11).

Outra corrente epistemológica, o apriorismo, inverte a relação estabelecida no empirismo. Se neste último, o mundo do objeto, o mundo físico, o exterior determinava o sujeito; na corrente apriorista ocorre o contrário. Isto é, o sujeito determina o objeto. A atividade de conhecimento é realizada de forma absoluta pelo sujeito, fazendo com que a experiência assuma pouca relevância nesse processo. Por isso, denomina-se apriorista 


\section{REVISTA ELETRÔNICA \\ DA GRADUAÇÃO/PÓS-GRADUAÇÃO EM EDUCAÇÃO UFG/REJ}

\section{ITINERPARUIS REFLECTIONIS}

ISSN. 1807-9342

Volume 14, N. 2, 2018

que vem de a priori, ou seja, as condições vêm predeterminadas no sujeito, em sua bagagem hereditária para possibilitar o conhecimento.

Enquanto no empirismo o aluno era tábula rasa, no apriorismo há o oposto, pois as estruturas do conhecimento fazem parte da bagagem hereditária do sujeito e estas irão se desenvolver pelos diferentes estágios por meio de um processo de maturação. $\mathrm{O}$ sujeito traz o conhecimento em sua herança genética. Logo, o meio físico ou social deve interferir o mínimo possível. Esta epistemologia está alinhada com a pedagogia nãodiretiva, a qual centra-se na ideia do laissez faire, isto é, deixar fazer. O papel do professor é relegado a segundo plano, ao passo que o aluno assume a responsabilidade de sua aprendizagem. Isso implica na retirada de uma tarefa primordial da prática docente que consiste na intervenção no processo de aprendizagem do aluno.

Destarte, o educando determina o educador, pois o primeiro já traz algo programado em seu sistema nervoso. O professor interfere o mínimo com conteúdo sobre as formas já existentes a priori. Apesar da relação sujeito-objeto e professor-aluno inverterem-se quando comparado ao empirismo, em ambos os casos se trata de uma relação assimétrica. Além disso, cabe destacar outro ponto em comum entre as epistemologias empirista e apriorista, qual seja: apresentam uma visão passiva de conhecimento, uma vez que as condições não dependem da atividade do sujeito, pois ou provêm do mundo exterior (empirista) ou já vêm programadas na bagagem hereditária do sujeito.

Ao considerar que o aluno traz em si o saber, o apriorismo subestima o papel docente e eleva o educando a um status muito superior às suas reais condições e à sua devida incumbência. Consequentemente, quando há fracasso do aluno no seu processo de aprendizagem, é o mesmo que deve assumir a responsabilidade. Esta postura exclui a função docente de conduzir o processo pedagógico e sobrecarrega o aluno em tarefas que exigem maior cuidado e atenção com o seu desenvolvimento cognitivo.

A pedagogia não-diretiva enxerga o professor como um facilitador, o qual deve apenas auxiliar o aluno na aprendizagem. $\mathrm{O}$ intento de pouco intervir no processo pedagógico justifica-se para não inibir a aprendizagem do educando. A distância do professor é necessária, pois o aluno é o centro do processo. Embora não se verifique um autoritarismo por parte do educador como ocorre na corrente empirista e na pedagogia diretiva, é atribuído ao aluno algumas qualidades que ele não possui, como "domínio do 


\section{REVISTA ELETRÔNICA \\ DA GRADUAÇÃO/PÓS-GRADUAÇÃO EM EDUCAÇÃO UFG/REJ}

\section{ITINERPARIIUS REFLECTIONIS}

ISSN. 1807-9342

Volume 14, N. 2, 2018

conhecimento sistematizado em determinada área, capacidade de abstração suficiente, especialmente na área de atuação específica do professor, e volume de informações devidamente organizadas, além, é claro, do domínio das didáticas" (BECKER, 1993, p. 10). Portanto, o aluno ainda não é reconhecido em suas características e necessidades próprias.

No tocante à epistemologia construtivista, percebe-se nitidamente uma mudança na forma como se estabelece a relação entre sujeito e objeto. As estruturas do conhecimento resultam de um processo de interação entre o mundo do sujeito e o mundo do objeto. Nesse sentido, não é o objeto que determina o sujeito nem o sujeito que determina o objeto, mas ambos interagem e determinam-se mutuamente. E como se dá esta interação? É preciso ressaltar que a interação é ativada através da ação do sujeito. Eis aqui o cerne da epistemologia construtivista: a ação do sujeito.

Piaget, um dos teóricos adeptos ao construtivismo, é também reconhecido como interacionista pelo fato de apresentar considerações alicerçadas sobre tal corrente que destaca a atividade do sujeito. Para o autor, o sujeito é um sujeito epistêmico, um sujeito do conhecimento, conforme supracitado. Por conseguinte, é um sujeito ativo em sua essência. A ação do sujeito é imprescindível para desencadear o processo de interação, porém não é suficiente. É fundamental o estímulo do meio, mas sujeito e meio somente constituem-se plenamente quando interagem. Deve-se esclarecer que a ação do sujeito sob a ótica do construtivismo piagetiano não significa qualquer ação, visto que diz respeito à ação de segundo nível. Ou seja:

Em outras palavras, trata-se da ação própria da tomada de consciência, da experiência lógico-matemática, da abstração reflexionante. Ação que, sem nunca abandonar totalmente a abstração empírica, a relativiza a tal ponto que o sujeito recorre a ela quando achar necessário, sem ser vítima pura e simples da pressão do meio. Seria este o ponto de chegada do verdadeiro sujeito epistêmico, condição de possibilidade do sujeito ético, do sujeito político, do sujeito humano, enfim (BECKER, 1993, p. 27).

O processo de interação se desenvolve com a finalidade de construir algo novo. Assim, explica-se a denominação construtivista. Visa-se produzir, criar, construir novos conhecimentos, o que justifica o fato de não haver determinações, nem por parte do sujeito nem por parte do objeto. $\mathrm{O}$ educador orientado por esta epistemologia ignora a 


\section{REVISTA ELETRÔNICA \\ DA GRADUAÇÃO/PÓS-GRADUAÇÃO EM EDUCAÇÃO UFG/REJ}

\section{ITINERARUIS REFLECTIONIS}

ISSN. 1807-9342

Volume 14, N. 2, 2018

ideia de que o aluno é tábula rasa ou que o conhecimento possa ser meramente transmitido, pois defende que o educando possui conhecimentos anteriores e experiências que podem servir de base para que novos conhecimentos sejam elaborados. Para tanto, apoia-se na pedagogia relacional, cujo pressuposto básico é o diálogo que permite a troca entre professor e alunos.

Esta epistemologia e a pedagogia estão em consonância com a concepção de educação problematizadora de Freire, a qual ratifica a importância do diálogo por propiciar a reflexão e ação. A relação dialógica entre professor e alunos permite, para além da troca de ideias, a construção conjunta de novos conhecimentos. Dessa maneira, torna-se possível que o professor conheça seus alunos, suas angústias, suas dúvidas, seus desejos e, principalmente, o momento em que se encontram no seu desenvolvimento cognitivo. A educação problematizadora contrapõe-se à repetição mecânica de conteúdos e estimula a criatividade, a curiosidade e a autonomia dos sujeitos.

Ao opor-se à noção de conhecimento pronto e acabado, a concepção de educação problematizadora também se ampara na consideração da historicidade dos seres humanos. Segundo Freire (2011, p. 83), "por isto mesmo é que os reconhece como seres que estão sendo, como seres inacabados, inconclusos, em e com uma realidade que, sendo histórica também, é igualmente inacabada". Logo, professor e alunos são seres inacabados em constante movimento de busca e construção de saber. Por consequência, as relações tonam-se mais fluidas e horizontais e observa-se o que a perspectiva freireana preconiza: o professor, além de ensinar, passa a aprender e o aluno, além de aprender passa a ensinar ao longo do processo de construção do conhecimento.

A postura docente assentada no construtivismo e na pedagogia relacional caracteriza-se por instigar a participação dos educandos, a exposição de suas inquietações, de seus conhecimentos prévios e, sobretudo, tem a finalidade de desacomodar o pensamento dos mesmos. As verdades cristalizadas são questionadas para que diferentes pontos de vista sejam expostos e discutidos e descobertas sejam realizadas. Sendo assim, o processo de aprendizagem construtivista diz respeito a um processo de aprendizagem ativo, no qual o aluno não se limite ao papel de mero depositário de conteúdos, mas que atue no sentido de (re)descobrir conhecimento. 


\section{REVISTA ELETRÔNICA}

DA GRADUAÇÃO/PÓS-GRADUAÇÃ̃O EM EDUCAÇÃO UFG/REJ

\section{ITHFPAPIIS REFLECTIONIS}

ISS N. 1807-9342

Volume 14, N. 2, 2018

Para tanto, é fundamental que o professor aprenda seu aluno, pois, ao se apropriar dos conceitos que este traz e como organiza seu pensamento, desvenda-se um horizonte de possibilidades que podem ser exploradas pelo educador no seu fazer pedagógico. Esta vertente pode ser associada ao terceiro tipo de professor apresentado por Marques (2005), conforme explicitado anteriormente. Trata-se do professor que pensa no aluno a partir do aluno, de modo que se distancia do seu egocentrismo para compreender como o aluno aprende. Busca-se compreender os processos de aprendizagem a fim de que estes sejam desenvolvidos com sentido ao educando e que assegurem seu avança em patamares mais abstratos e complexos.

Um ensino de Geografia construtivista pressupõe uma atitude docente coerente com tal linha teórico-epistemológica. Todavia, Becker (1993, p. 39) argumenta que "mesmo os docentes com posições aprioristas/inatistas ou que se aproximam de uma postura interacionista não conseguem superar totalmente sua epistemologia empirista. Numa palavra, todos os docentes são, pelo menos em algum grau, empiristas”.

Esta constatação é justificada pela própria naturalização do empirismo nas práticas docentes por ser a epistemologia mais presente historicamente nas salas de aula, além de inquestionável quanto à sua legitimidade. Por outro lado, isso não significa que nós, professoras e professores de Geografia, não possamos desconstruir ideias arraigadas em nossas concepções e fazeres com o intuito de aproximarmos dos princípios que nos identificamos. Isso requer, de forma primordial, a clareza de que:

Dar aulas de geografia" não é a mesma coisa que geografizar. 'Dar' significa não cobrar, não se preocupar com as devoluções. 'Fazer geografia' é buscar constantemente as explicações e argumentar, é construir as condições necessárias para entender como se processam as relações que compõem o espaço (COSTELLA, 2015, p. 39)

Geografizar, nesse sentido, está relacionado a um processo de construção do conhecimento que vise compreender o espaço geográfico e suas relações, considerando suas contradições e complexidade. É muito mais que localizar países e capitais e classificar o relevo. É criar possibilidades e situações de aprendizagem que permitam ao educando compreender sua realidade sócio-espacial, assim como ser capaz de articular com outros espaços e escalas mais abrangentes. Este caminho pode promover uma autonomia de pensamento e uma atitude crítica, reflexiva e participativa na sociedade. 


\section{REVISTA ELETRÔNICA \\ DA GRADUAÇÃO/PÓS-GRADUAÇÃO EM EDUCAÇÃO UFG/REJ}

\section{ITINEPARIUS REFLECTIONIS}

ISSN. 1807-9342

Volume 14, N. 2, 2018

Por isso, não basta dar aulas de Geografia; é preciso geografizar. A epistemologia construtivista e as considerações de Piaget podem oferecer subsídios para esta empreitada. A seção seguinte pretende apresentar algumas pistas para que o caminho seja menos esburacado e desgastante de ser percorrido.

\section{O CONSTRUTIVISMO, PIAGET E O ESPAÇO GEOGRÁfiCO: relações possíveis}

O processo de construção do espaço é um longo caminho percorrido por todos nós, procedendo da ação para a operação (OLIVEIRA, 2005; 2007). Por ser desta forma é que a Epistemologia Genética de Jean Piaget (2012) ganha importância dentro da Geografia escolar. Mesmo que este autor não tenha pesquisado diretamente a construção do espaço geográfico por parte da criança, o seu pensar ganha imersão dentro deste campo por suas variáveis que tangenciam essa construção.

Se pegarmos os títulos de parte das publicações de Jean Piaget, clarificam-se as razões de seu uso em sala de aula: "A gênese do número na criança"; "O desenvolvimento das quantidades fisicas na criança"; "O nascimento da inteligência na criança"; "A linguagem e o pensamento da criança"; "O raciocínio na criança", são somente algumas das obras no vasto compêndio de publicações de Piaget e sua equipe que refletem um rico material de observação e reflexão que possibilitam um pensar sobre o ensino e a aprendizagem.

Mas, mesmo com o ideário interacionista que delineou os moldes da Escola Nova, os professores persistem pautando suas práticas em outras epistemologias que apresentam uma falta de compreensão da natureza do pensamento humano. Mesmo o ideário interacionista pautado na ação do sujeito não ser algo recente, como bem destaca Gadotti (1999), suas ideias ainda são mal compreendidas e mesmo distorcidas quando utilizadas em sala de aula.

A Escola Nova representa o mais vigoroso movimento de renovação da educação depois da criação da escola pública burguesa. A ideia de fundamentar o ato pedagógico na ação, na atividade da criança, já vinha se formando desde a "Escola Alegre" de VITORINO DE FELTRE (1378-1446), seguindo pela pedagogia romântica e 


\section{REVISTA ELETRÔNICA \\ DA GRADUAÇÃO/PÓS-GRADUAÇÃO EM EDUCAÇÃO UFG/REJ}

\section{ITINERPARUS REFLECTIONIS}

ISSN. 1807-9342

Volume 14, N. 2, 2018

naturalista de Rousseau. Mas foi só no início do século XX que tomou forma concreta e teve consequências importantes sobre os sistemas educacionais e a mentalidade dos professores (GADOTTI, 1999, p.142).

Quando pensamos a epistemologia genética, percebemos que não é o professor o responsável pela construção do conhecimento, mas, ele ainda desempenha papel importante dentro do cenário educacional. Parte de seu ideário uma gama de possibilidades para se desequilibrar o aluno, fazendo com que este reaprenda, no plano do pensamento, o que já havia apreendido no plano da ação, tendo desta forma uma nova estruturação que possibilitará pensar o espaço geográfico de forma relacional, não mais apenas como sendo um espaço absoluto que se fecha em si mesmo.

Costella e Schäffer (2012, p.42) comentam diferentes enfrentamentos por parte do professor dentro da sala de aula, um que se preocupa com "vencer" os conteúdos no ano letivo, e, outro que se atenta com o desenvolvimento construtivo do seu aluno, com uma postura de descobridor e não receptor deste, essas são duas posturas epistemológicas distintas que impactam no pleno desenvolvimento do sujeito.

Quando o professor trabalha isolado, preocupado com a instrução sobre conteúdos, fragmentando, compartimentando conceitos, predomina o interesse em vencer um conjunto de informações, em finalizar compromissos formais. Ao se preocupar com os processos que representam a possibilidade de aprendizagem e ao se envolver em projetos integradores, o professor se mostra sensível à memória de si mesmo, à compreensão que teve na mesma idade e à vontade de aprender que têm hoje seus alunos, tão sedentos por caminhos que os tornem mais descobridores do que receptores, como também fomos.

As correntes empiristas e aprioristas compartilham um conhecimento que é abordado pelo vértice do fato e não do processo, em que as respostas são feitas ou encontram-se prontas na figura do professor ou mesmo do indivíduo enquanto organismo que não se encontra desenvolvido de forma suficiente. O que Piaget nos ensinou foi a percepção do conhecimento enquanto processo, em que a ação do sujeito vai de forma gradativa abrindo novas janelas e propondo novos debates, desta forma "o conhecimento não é mais um estado, mas sim um processo" (OLIVEIRA, 2007, p.165).

Essa posição de ver o conhecimento enquanto um vir-a-ser é a única posição epistêmica a se ter quando pensamos na construção do espaço geográfico dentro da Geografia escolar. Este espaço se dá a partir da multiplicidade de coexistências que o 


\section{REVISTA ELETRÔNICA \\ DA GRADUAÇÃO/PÓS-GRADUAÇÃO EM EDUCAÇÃO UFG/REJ}

\section{ITINERPARIIUS REFLECTIONIS}

ISSN. 1807-9342

Volume 14, N. 2, 2018

fazem enquanto objeto a ser conhecido, tarefa essa que cabe em parte a instituição escola, que concentra papel primordial dentro deste processo, ao ser lugar de debates sobre as culturas locais e globais.

Sobre o espaço, fazemos nossas as palavras de Massey (2013, p.29):

Primeiro, reconhecemos o espaço como o produto de inter-relação, como sendo constituído através de interações, desde a imensidão do global até o intimamente pequeno. [...] segundo, compreendemos o espaço como a esfera da possibilidade da existência da multiplicidade, no sentido da pluralidade contemporânea, como a esfera na qual distintas trajetórias coexistem; como a esfera, portanto, da coexistência da heterogeneidade. Sem espaço, não há multiplicida de; sem multiplicidade, não há espaço. Se espaço é, sem dúvida, o produto de inter-relações, então deve estar baseado na existência da pluralidade. Multiplicidade e espaços são co-constitutivos. Terceiro, reconhecemos o espaço como estando sempre em construção.

Este espaço costurado a partir da diversidade de aromas, sotaques, sons e tonalidades de peles é formado a partir de diferentes etapas de desenvolvimento, como nos bem ensina Piaget (PIAGET; INHELDER, 1993; 2013; PIAGET, 1967; 1973), e, é neste ínterim que conhecer a teoria construtivista piagetiana ganha relevo, ao mostrar ao professorado as possibilidades que um aluno apresenta em diferentes etapas de sua vida.

Ele nos ensina, por exemplo, que trabalhar com mapas na parede com crianças pequenas é um grande desserviço a essas, uma vez que, esses produtos cartográficos apresentam um alto grau de abstração que uma criança pequena não consegue assimilar. Outro ponto é a questão da lateralidade, sendo que não devemos trabalhar essa questão a partir de exemplos distantes à criança, sendo necessário inicialmente partir de seu próprio corpo, para, somente por meio deste ponto, partir para distâncias maiores. Como destaca Oliveira (1978, p.99):

Ninguém espera que uma criança seja iniciada no processo de leitura e escrita da língua portuguesa através do conteúdo e da forma de "Grandes Sertões: Veredas", de João Guimarães Rosa. Muito menos alguém aceitaria que uma criança começasse seus estudos de Matemática mediante a demonstração de teoremas e postulados de Thom. Por isso perguntamos: por que iniciar a criança no mundo da linguagem gráfica com mapas que implicam projeções, escalas e generalizações altamente abstratas?

O professor Couto (2017, p.15) comentando sobre os conceitos geográficos destaca que estes são abstrações que auxiliam na construção espacial, é a partir deles 


\section{REVISTA ELETRÔNICA \\ DA GRADUAÇÃO/PÓS-GRADUAÇÃO EM EDUCAÇÃO UFG/REJ}

\section{ITINEPARIUS REFLECTIONIS}

ISSN. 1807-9342

Volume 14, N. 2, 2018

que desenvolvemos nossa leitura do espaço, mas se eles são categorias abstratas, os alunos seriam capazes de compreendê-los em qualquer etapa de sua vida escolar? Piaget nos mostra que não.

Saberes, categorias empíricas e conceitos geográficos, são abstrações que expressam (e constroem) a práxis espacial, sua percepção, descrição e/ou interpretação. Estas abstrações se movimentam entre um polo mais prático - o da prática e da percepção espacial - e outro mais teórico - o da interpretação da constituição geográfica das sociedades no seu todo dinâmico-estrutural.

Desta forma, os níveis de desenvolvimento (sensório-motor-pré-operatórioconcreto-formal) precisam ser compreendidos para possibilitar um diálogo mais aberto com os alunos que, junto a nós constrói, o espaço geográfico. Assim, estaremos em um lócus em que se torna passível de se assimilar a noção de espaço como um conceito que emerge de elementos teóricos e práticos. Teórico, pois é de sua essência a representação, por exemplo, que trabalha a partir de signos e se projeta sobre proposições e hipóteses; prático, uma vez que, é na vivência cotidiana que construímos as primeiras estruturas que possibilitam compreendê-lo de forma relacional.

Ao aluno saber ler o seu lugar, será possível estender esta leitura a outros lugares, que, mesmo não vivenciados de forma direta, acabam por influir em seu modo de vida. A criança progressivamente desenvolve estruturas que permitem reorganizar mentalmente distintas hipóteses, desenvolvendo tantas ações quantas forem necessárias para resolver problemas de cunho acadêmico, bem como, ao que tange a vida prática, como se orientar em uma cidade desconhecida, ler um mapa, saber escolher o melhor acento em um ônibus ou avião dependendo a hora do dia, selecionar o local para a horta caseira, até soluções mais sofisticadas de marketing, bem como, questões relativas ao trânsito e à poluição urbana, por exemplo.

Por fim, o construtivismo nos concede uma ação prática e teórica mais aberta frente aos atores envolvidos no processo de aprendizagem; Piaget nos dá o conhecimento de como agir frente a diferentes públicos, como forma de potencializar nossas práticas pedagógicas diante do desenvolvimento construtivo dos alunos; e, o espaço geográfico, delineia as categorias geográficas que se mesclam aos conteúdos escolares, afim de (re)conhecê-los enquanto parte importante do processo de aprendizagem. 


\section{REFERÊNCIAS}

AEBLI, Hans. Una didáctica fundada en la psicología de Jean Piaget. Buenos Aires: Editora Kapelusz, 1958.

BARRELET, Jean-Marc; PERRET-CLERMONT, Anne-Nelly. Jean Piaget aprendiz e mestre. tradução Fernanda Oliveira. Lisboa: Instituto Piaget, s/data.

BECKER, Fernando. A epistemologia do professor: o cotidiano da escola. Rio de Janeiro: Vozes, 1993.

2001.

Educação e cons trução do conhecimento. Porto Alegre: Artmed Editora,

COSTELLA, Roselane Zordan. Para onde foi a geografia que penso ter aprendido. In: CASTROGIOVANNI, Antonio Carlos (Orgs. et al.). Movimentos no ensinar geografia: rompendo rotações. Porto Alegre: Evangraf, 2015. p.29-40.

COSTELLA, Roselane Zordan; SCHÄFFER, Neiva Otero. A Geografia em projetos curriculares: ler o lugar e compreender o mundo. Erechim: Edelbra, 2012.

COUTO, Marcos Antonio Campos. A geografia como ciência das práticas e dos saberes espaciais - por um novo modelo clássico de organização curricular. In: Revista Tamoios, São Gonçalo (RJ), ano 13, n. 2, p. 5-25, jul-dez 2017. Disponível em: <http://www.e-publicacoes.uerj.br/index.php/tamoios/article/view/30150/22581>. Acesso em: 15 jan. 2018.

DAMÁSIO, António Rosa. O mistério da consciência: do corpo e das emoções ao conhecimento de si. tradução Laura Teixeira Motta. São Paulo: Companhia das Letras, 2000 .

DREHER, Felipe. SOUSA, Paulo Henrique. Na matemática, o impossível é para sempre impossível. Cálculo: matemática para todos. São Paulo, v.43, ano 4, p.24-33, ago. 2014.

FREIRE, Paulo. Conscientização: teoria e prática da libertação: uma introdução ao pensamento de Paulo Freire. São Paulo: Cortez \& Moraes, 1979.

Pedagogia do oprimido. 50. ed. Rio de Janeiro: Paz e Terra, 2011.

GADOTTI, Moacir. História das idéias pedagógicas. 7. ed. São Paulo: Editora Ática, 1999.

KAERCHER, Nestor André. Os movimentos que meus mestres me ensinam: ddd's, signos, alimentos, escadas, luzes, grenais. In: CASTROGIOVANNI, Antonio Carlos.; TONINI, Ivaine Maria.; KAERCHER, Nestor André (Orgs.). Movimentos no ensinar geografia. Porto Alegre: Imprensa Livre: Compasso Lugar-Cultura, 2013. p.13-34. 
MARQUES, Tania Beatriz Iwaszko. Do egocentrismo à descentração: a docência no ensino superior. 2005. 263 f. Tese (Doutorado em Educação) - Universidade Federal do Rio Grande do Sul, Porto Alegre, 2005.

MASSEY, Doreen. Pelo espaço: uma nova política da espacialidade. tradução Hilda Pareto Maciel e Rogério Haesbaert. 4. ed. Rio de Janeiro: Bertrand Brasil, 2013.

MENEZES, Victória Sabbado. Geografia escolar: as concepções teóricas e epistemologia da prática do professor de Geografia. 2016. 204 f. Dissertação (Mestrado em Geografia) - Instituto de Geociências, UFRGS, 2016.

OLIVEIRA, Lívia de. A construção do espaço, segundo Jean Piaget. In: Sociedade \& Natureza, Uberlândia, v.17, n.33, p.105-117, dez. 2005. Disponível em: <www.seer.ufu.br/index.php/sociedadenatureza/article/view/9205/5667>. Acesso em: 08 jan. 2018.

Uma leitura geográfica da epistemologia do espaço segundo Piaget. In: VITTE, Antonio Carlos (Org.). Contribuições à história e à epistemologia da geografia. Rio de Janeiro: Bertrand Brasil, 2007. p.163-188.

PIAGET, Jean; BETH, Willem Evert; MAYS, Wolfe. Epistemologia genética e pesquisa psicológica. tradução Equipe da Livraria Freitas Bastos. Rio de Janeiro: Freitas Bastos, 1974.

PIAGET, Jean. O raciocínio na criança. tradução de Valerie Rumjanek Chaves. 2. ed. Rio de Janeiro: Editora Record, 1967.

. Problemas de psicologia genética. tradução Celia E. A. Di Piero. Rio de Janeiro: Editora Forense, 1973.

A linguagem e o pensamento da criança. tradução de Manuel Campos. 6. ed. São Paulo: Martins Fontes, 1993.

Epistemologia genética. tradução Álvaro Cabral. 4. ed. São Paulo: Editora WMF Martins Fontes, 2012.

VASCONCELOS, Mário Sérgio. A difusão das ideias de Piaget no Brasil. São Paulo: Casa do Psicólogo, 1996. 